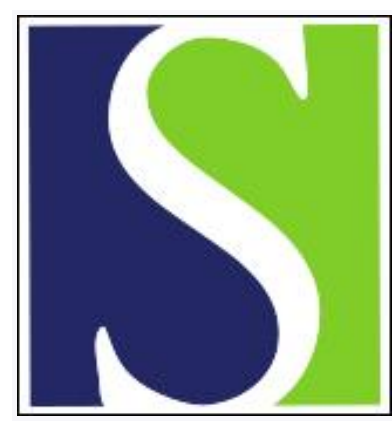

Scand J Work Environ Health 1996;22(1):67

https://doi.org/10.5271/sjweh.113

Issue date: Feb 1996

\title{
Mesothelioma in oil refinery workers
}

by Finkelstein $M$

Refers to the following text of the Journal: 1995;21(4):301-309

The following article refers to this text: SJWEH Supplements 2009;(7):41-47

This article in PubMed: www.ncbi.nlm.nih.gov/pubmed/8685679

\section{(c) (i)}




\section{Mesothelioma in oil refinery workers}

I read with interest the exchange of correspondence between Wong (1) and Gennaro et al (2) concerning the issue of pleural mesothelioma in oil refinery workers. I recently had occasion to investigate this issue in Ontario after being contacted by a man who had worked as an insulator in a refinery and who had been diagnosed with pleural mesothelioma. Lambton County is the home of much of Ontario's refining and petrochemical industry. Between 1976 and 1985, there were 13 deaths from mesothelioma. Lambton County ranked first for the rate of pleural mesothelioma and fourth for the rate of peritoneal mesothelioma in men (3). The standardized mortality ratio (SMR) for lung cancer for men in the County was 1.06 [95\% confidence interval $(95 \%$ CI) $0.96-$ $1.17]$ in comparison with that for men from other provincial census divisions.

I undertook a case-referent analysis based on the use of death certificates using information from the Ontario Mortality Registry from 1980 to 1992 . There were two objectives for the investigation. First, we wished to assess the association between employment in the refinery and petrochemical sector and mesothelioma in the County. Second, it was hypothesized that, since maintenance employees in that sector had an increased risk of mesothelioma attributable to asbestos exposure, they might also be at increased risk of lung cancer, despite evidence that there was no overall increase in the risk of lung cancer among workers in the refinery and petrochemical sector.

Ten of the men with mesothelioma were from the refinery and petrochemical sector. All had pleural mesothelioma listed on their death certificate. Six had been employed as maintenance workers, one had been a pumphouse operator, one a process operator, and two were retired from this sector with job unspecified on the death certificate. Eight of 46 referents were from the refinery and petrochemical sector. One of 46 had been employed as a maintenance worker, six had been employed in process work, and one in clerical work. The odds ratio for mesothelioma among the maintenance workers in the refinery and petrochemical sector was 24.5 (90\% CI $3.1-102$ ).

The risk of lung cancer among all the petrochemical workers, in comparison with all other workers in the country, was 0.88 . In an internal comparison of maintenance employees with other blue-collar workers in the refinery and petrochemical sector, we found that 28 of 50 maintenance employees had been diagnosed with lung cancer compared with 21 of 50 other blue-collar workers. The odds ratio for lung cancer was $1.73(90 \% \mathrm{CI}$ $0.83-3.6$ ). This finding might be compared with the SMR of 197 (95\% CI 113-320) reported by Gennaro et al (2) in their internal comparison of maintenance workers and other employees.

I conclude that there is likely an association between maintenance work in the refinery and petrochemical sector and an increased risk of asbestos-associated tumors. We are planning additional case-referent studies in follow-up.

\section{References}

1. Wong O. Pleural mesothelioma in oil refinery workers [letter]. Scand J Work Environ Health 1995;21:301-3.

2. Gennaro V, Ceppi M, Fontana V, Perrotta A, Silvano S, Boffetta P. Author's reply [letter]. Scand J Work Environ Health 1995;21:303-9.

3. Marrett LD, Swift MB, Reynolds DL, Clarke EA. Geographic distribution of cancer in Ontario; vol 1. Toronto (Canada): Ontario Cancer Treatment and Research Foundation, 1991.

\section{Murray Finkelstein, $M D^{1}$}

1 Ontario Ministry of Labour

Health and Safety Studies Unit

400 University Avenue

7th Floor

Toronto

Ontario M7A IT7

Canada 